\title{
SELECTIVE FETOSCOPIC LASER PHOTOCOAGULATION OF SUPERFICIAL PLACENTAL ANASTOMOSES FOR THE TREATMENT OF SEVERE TWIN-TWIN TRANSFUSION SYNDROME
}

\author{
Rodrigo Ruano, Maria de Lourdes Brizot, Adolfo Wenjaw Liao, Marcelo Zugaib
}

doi: $10.1590 / \mathbf{S 1 8 0 7 - 5 9 3 2 2 0 0 9 0 0 0 2 0 0 0 0 5}$

Ruano R, Brizot ML, Liao AW, Zugaib M. Selective fetoscopic laser photocoagulation of superficial placental anastomoses for the treatment of severe twin-twin transfusion syndrome. Clinics. 2009;64:91-6.

OBJECTIVE: To report our initial institutional experience with fetoscopic laser photocoagulation of placental anastomoses in severe twin-twin transfusion syndrome using a $1.0 \mathrm{~mm}$ endoscope.

METHODS: Between July 2006 and June 2008, 19 monochorionic diamniotic twin pregnancies complicated by severe TTTS (Quintero stages III and IV) underwent fetoscopic laser therapy. Perinatal data were prospectively collected and compared according to the Quintero stages.

RESULTS: Nine patients were classified as stage III and ten as stage IV. The Mean gestational ages at diagnosis and procedure were 20 (range: 17-25) and 22.0 (range: 19.0-26.0) weeks, respectively, with no statistical difference between the two groups. Preterm premature rupture of the membranes occurred in two cases (10.5\%), and spontaneous preterm delivery in eight (42.1\%). Overall mean gestational age at delivery was 32.1 (range: 26.0-38.0) weeks. Prematurity was more severe in stage IV patients $(p<0.01)$. Among all cases, the overall survival rate was $52.6 \%$, and the percentages of pregnancies with survival of both babies and at least one twin were $26.3 \%$ and $78.9 \%$, respectively. In the case of stage III patients, the overall survival rate was $61.1 \%$. Of the stage III pregnancies, $33.3 \%$ resulted in both babies surviving, and $88.9 \%$ of these pregnancies resulted in at least one surviving twin. For stage IV, as the corresponding statistics were $45.0 \%, 20.0 \%$ and $70.0 \%$ respectively.

CONCLUSIONS: Our initial institutional experience with $1.0 \mathrm{~mm}$ fetoscopic laser therapy for severe TTTS showed results similar to those reported in the literature for larger endoscopes.

KEYWORDS: Twin-twin transfusion syndrome; Fetal surgery; Fetoscopy; Prenatal diagnosis; Laser; Fetal therapy; Placenta; Monochorionic twins.

\section{INTRODUCTION}

Monochorionic twin pregnancies represent a high-risk group for adverse obstetric outcomes. ${ }^{1}$ In approximately $10 \%$ of monochorionic twin pregnancies, unbalanced inter-twin blood flow along placental vascular anastomoses can cause twin-twin transfusion syndrome (TTTS) ${ }^{2,3}$ Left untreated, the prognosis is poor, with high perinatal mortality rates of

Obstetrics Department, Universidade de São Paulo, Faculdade de Medicina da Universidade de São Paulo/SP, Brazil

Email: rodrigoruano@hotmail.com

Tel.: 5511 6601-6280

Received for publication on August 04, 2008

Accepted for publication on October 17, 2008
$80-100 \%$ and a substantial risk of neurological sequelae in survivors. ${ }^{4,5}$

Numerous prenatal treatment options for TTTS have been reported including amnioreduction (AR), ${ }^{6-9}$ inter-twin septostomy, ${ }^{10-14}$ nonselective fetoscopic laser ablation ${ }^{15-17}$ and selective laser photocoagulation of placental anastomoses. ${ }^{18-26}$ Although the pathophysiology of the disease is poorly understood, TTTS is attributed to unbalanced inter-twin blood flow along superficial placental anastomoses. Therefore, fetoscopic laser photocoagulation of inter-twin superficial placental anastomoses has been described as the best option for prenatal treatment of TTTS. ${ }^{18-25}$ This prenatal procedure was first described by De Lia et al. ${ }^{26}$ in 1990 as a means of functionally occluding vascular connections responsible for 
the syndrome. Many controversial results have been reported in the literature, but multiple studies suggest that fetoscopic laser photocoagulation of superficial placental anastomoses remains the best option for severe TTTS. ${ }^{19,22,24,25}$ In 2004, Senat et al. ${ }^{19}$ demonstrated that fetoscopic laser photocoagulation of placental anastomoses was a more effective first-line treatment than serial amnioreduction. In general, the percentages of pregnancies with survival of both fetuses vary from $40 \%$ to $60 \%$. The rate for survival of at least one twin ranges from $70 \%$ to $90 \%$. This variation in perinatal outcome might be explained by different stages of TTTS.

The severity of the disease is usually assessed by the Quintero staging system: ${ }^{27}$ Stage I is defined as oligohydramnios (deepest vertical pool $\leq 2 \mathrm{~cm}$ ) in the donor and polyhydramnios (deepest vertical pool $\geq 8 \mathrm{~cm}$ ) in the recipient; Stage II is denoted by donor anuria (anamnios and absence of fetal bladder - "stuck twin"); Stage III is characterized by critically abnormal Doppler ultrasonography in either the arterial system of the donor or the venous system of the recipient; Stage IV is present when there is fetal hydrops; and Stage V occurs with the mortality of one or both twins.

To the best of our knowledge, most centers use endoscopes of 2.0 to $3.0 \mathrm{~mm}$ to guide the fetoscopic laser ablation of superficial placental anastomoses, and there have been no previous reports of the use of a narrower endoscope for this procedure.

Therefore, the objective of the present study was to report our initial clinical experience with fetoscopic laser photocoagulation for severe TTTS using a $1.0 \mathrm{~mm}$ endoscope, focusing on perinatal outcomes and maternal complications consistent with the Quintero staging standard.

\section{METHODS AND PATIENTS}

From July 2006 to June 2008, a prospective study was conducted in a tertiary fetal medicine center. Fetoscopic laser photocoagulation was performed in 19 monochorionic diamniotic twin pregnancies complicated by severe TTTS. All patients were referred from obstetricians or other fetal medicine centers. All patients gave written consent after extensive counseling. This protocol was approved by the local ethical committees. Before laser treatment, detailed fetal morphological ultrasound examination and echocardiography were performed in order to assess fetal biometry, anomalies, deepest vertical pool, placental location and Doppler sonography of the umbilical arteries, middle cerebral arteries and ductus venosus.

Inclusion criteria for fetoscopic laser photocoagulation were: monochorionic diamniotic pregnancies complicated with severe TTTS (polyhydramnios in the recipient twin's amniotic cavity with the deepest vertical pool $\geq 8 \mathrm{~cm}$ and oligohydramnios in the donor twin with the deepest vertical pool $\leq 2 \mathrm{~cm}$; Stages III and IV according to the Quintero classification $^{27}$ ) at a gestational age of less than 26 weeks. Exclusion criteria were fetal death, fetal malformation before procedure, rupture of membranes and preterm labor. During the study period, fetoscopic laser therapy was not offered for Stage I TTTS.

Fetoscopic laser therapy of the superficial placental anastomoses was performed under local maternal anesthesia $(20 \mathrm{ml}$ of $1 \%$ lidocaine injected into the skin and subcutaneous tissue) followed by percutaneous insertion into the amniotic cavity of a $2.2 \mathrm{~mm}$ specially designed trocar with two separate work channels for a 1 $\mathrm{mm}$ fetoscope (11510 A, Storz, Tuttlingen, Germany) and a $0.6 \mathrm{~mm}$ neodymium fiber, to allow the use of yttriumaluminum-garnet or diode laser equipment. In pregnancies with a completely anterior placenta, we used a $30^{\circ}$ trocar of the same size and diameter. Superficial inter-twin placental anastomoses were directly identified (Figure 1a) and coagulated (Figures 1b-d). At the end of the selective laser ablation procedure, amniotic fluid was drained through the sheath after removing the fetoscope until a vertical pool of 4-6 cm was confirmed under ultrasound. Prophylactic tocolytics and antibiotics were administered perioperatively. All the patients were hospitalized for 24 to 48 hours after the procedure and were followed by weekly ultrasound examinations.

The following prenatal and neonatal data were collected prospectively: gestational age at diagnosis, gestational age at fetoscopic laser photocoagulation, survival rates (either both fetuses or at least one twin), fetal mortality and neurological morbidity (intraventricular hemorrhage, periventricular

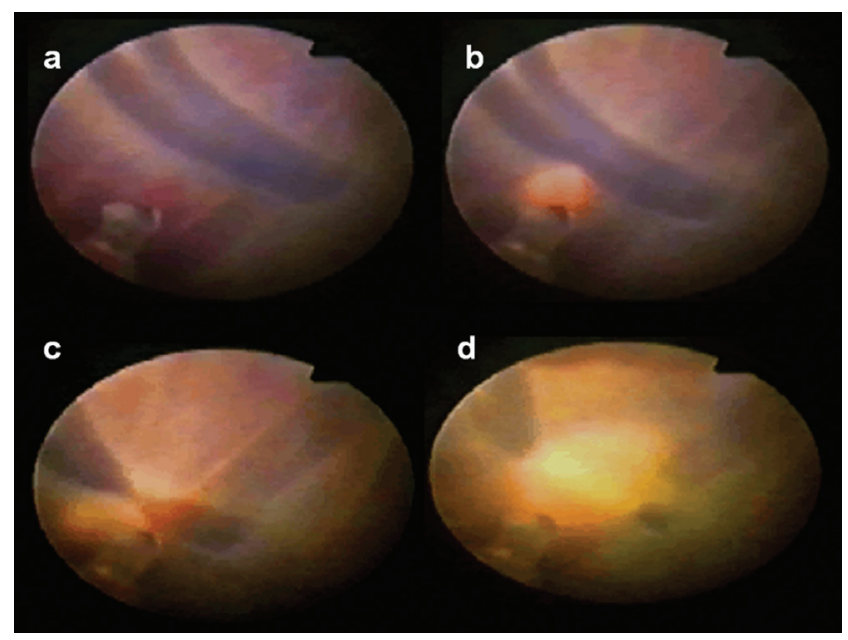

Figure 1 - (a) Fetoscopic view of superficial inter-twin vascular anastomoses in a TTTS stage III pregnancy at 22 weeks of gestation. (b,d) Fetoscopic laser photocoagulation of superficial inter-twin anastomoses. 
leukomalacia, ventriculomegaly or cerebral palsy) during hospitalization for up to 30 days. All data were analyzed according to the Quintero stage. Categorical variables such as survival and stage were analyzed using the $\chi^{2}$ test. Interval variables such as gestational age were analyzed using the Student's t test. Statistical significance was confirmed when $p \leq 0.05$.

\section{RESULTS}

A total of 23 monochorionic diamniotic pregnancies met the initial inclusion criteria. However, three patients were excluded because preterm labor occurred before the laser procedure could be performed. One additional patient was excluded because she was bearing triplets. For the 19 pregnancies that were included in the present study, severe TTTS (stages III and IV) was confirmed using ultrasound examination. The mean gestational age at diagnosis was 20 (range: 17-25) weeks. Nine pregnancies were classified as stage III, and ten as stage IV.

The mean gestational age at fetoscopic laser ablation was 22.0 (range: 19.0-26.0) weeks. There was no statistical difference in gestational age at the time of the procedure between patients with TTTS stage III (mean: 21.0; range: 20.0-25.0) and those with stage IV (mean: 22.0; range: $19.0-26.0 ; p=0.38$ ). The number of anastomoses coagulated per procedure varied from 7 to 13 and was similar in both groups $(p=0.42)$. The placenta was posterior in $10 / 19$ $(52.6 \%)$ pregnancies and anterior in $9 / 19(47.4 \%)$. In the present study, a second fetoscopic laser coagulation was not required for any of the cases. There were no serious maternal complications during or after fetoscopy. There was no need for blood transfusion, laparotomy or admission to an intensive care unit.

Preterm premature rupture of the membranes (PPROM) occurred in 2/19 (10.5\%) pregnancies (one was a TTTS stage III patient and the other was stage IV). In the first case, PPROM occurred two weeks after the procedure, which was performed at 24 weeks of gestation. At 26 weeks, the patient delivered vaginally and both twins died on the second day of life. A second patient with stage III TTTS underwent fetoscopic laser therapy at 25 weeks. PPROM occurred seven weeks after fetoscopic laser therapy. The patient delivered one baby who is currently healthy (the donor twin died two days after laser therapy).

Recurrence of polyhydramnios in the recipient's amniotic sac occurred in $3 / 19$ (15.8\%) pregnancies in which both twins survived after fetoscopic laser photocoagulation. In one patient, polyhydramnios recurred eight weeks after the procedure, and two amnioreductions were performed. The donor, who had already exhibited ventriculomegaly before the laser procedure, died in utero at 30 weeks of gestation. A Caesarean section was performed at 32 weeks; the recipient is currently healthy. In another patient, recurrence of polyhydramnios was observed four weeks after fetoscopic laser coagulation, and three amnioreductions were performed; the donor died in utero at 29 weeks. A Caesarean section was performed because of fetal distress and meconium at 31 weeks. The recipient died two days after birth. In a third patient, recurrent polyhydramnios was diagnosed three weeks after the procedure and three amnioreductions were performed. In this patient, tocolytic medication (beta-agonist) was used continuously from 22 to 26 weeks, and a Caesarean section was performed at 26 weeks of gestation. However, the recipient died one day after birth and the donor one week later.

Spontaneous preterm labor occurred in 8/19 (42.1\%) pregnancies. In a further $5 / 19(26.3 \%)$ pregnancies, patients were delivered prematurely before 32 weeks because of fetal distress. The overall mean gestational age at delivery was 32.1 (range: 26.0-38.0) weeks of gestation. Prematurity was more severe among pregnancies with stage IV disease (mean: 31.3 weeks; range: 26.0 - 36.0) than among those classified as stage III (mean: 33.8 weeks; range: 30.0 - 38.0; $p<0.01)$.

Perinatal results are shown in Table 1 . The overall survival rate was $52.6 \%$ (20/38). The percentage of pregnancies in which both twins survived was $26.3 \%$ (5/19). Survival of only one twin occurred in $52.6 \%$ of cases (10/19), thus resulting in a survival rate for at least one baby of $78.9 \%(15 / 19)$. The survival rates for recipient and donor twins were similar at $52.6 \%(10 / 19)$. Recipient fetal mortality occurred in $31.6 \%$ (6/19) of cases while mortality of the donor fetus occurred in $36.8 \%$ (7/19). Neonatal deaths occurred in $3 / 19(15.8 \%)$ of recipient babies and in $2 / 19(10.5 \%)$ of donor babies. Among all survivors $(n=20)$, there was no intraventricular hemorrhage, periventricular leukomalacia, ventriculomegaly or cerebral palsy detected at up to 30 days of life. In one case, a disproportionally smaller right leg of the recipient twin was noted at birth after 29 weeks of gestation (the donor died one day after fetoscopic laser therapy at 26 weeks).

According to the Quintero stages, there was a tendency for increased perinatal survival for stage III TTTS as compared to stage IV cases; however this difference did not reach statistical significance (Table 1). There was no cerebral morbidity among the 17 babies that survived.

\section{DISCUSSION}

This study presents our initial institutional experience with fetoscopic laser photocoagulation for the treatment of 
Table 1 - Perinatal results of 19 pregnancies with TTTS stages III and IV treated with fetoscopic laser photocoagulation

\begin{tabular}{|c|c|c|c|c|}
\hline & \multicolumn{3}{|c|}{ Quintero stage } & \multirow{2}{*}{$p$ value } \\
\hline & All cases & III & IV & \\
\hline Gestational age at procedure & $22.0(19.0-26.0)$ & $22.0(20.0-25.0)$ & $21.9(19.0-26.0)$ & 0.38 \\
\hline Gestational age at delivery & $32.1(26.0-38.0)$ & $33.8(30.0-38.0)$ & $31.3(26.0-36.0)$ & $<0.01$ \\
\hline Overall survival rate & $20 / 38(52.6 \%)$ & $11 / 18(61.1 \%)$ & $9 / 20(45.0 \%)$ & 0.32 \\
\hline At least 1 survivor & $15 / 19(78.9 \%)$ & $8 / 9(88.9 \%)$ & $7 / 10(70.0 \%)$ & 0.31 \\
\hline One survivor & $10 / 19(52.6 \%)$ & $5 / 9(55.6 \%)$ & $5 / 10(50.0 \%)$ & 0.81 \\
\hline Both survivors & $5 / 19(26.3 \%)$ & $3 / 9(33.3 \%)$ & $2 / 10(20.0 \%)$ & 0.51 \\
\hline Donor intrautero death & $7 / 19(36.8 \%)$ & $4 / 9(44.4 \%)$ & $3 / 10(30.0 \%)$ & 0.51 \\
\hline Recipient intrautero death & $6 / 19(31.6 \%)$ & $1 / 9(11.1 \%)$ & $5 / 10(50.0 \%)$ & 0.07 \\
\hline Donor neonatal death & $2 / 19(10.5 \%)$ & $1 / 9(11.1 \%)$ & $1 / 10(10.0 \%)$ & 0.94 \\
\hline Recipient neonatal death & $3 / 19(15.8 \%)$ & $1 / 9(11.1 \%)$ & $2 / 10(20.0 \%)$ & 0.59 \\
\hline
\end{tabular}

* Means (range) $-t$ student test; ** Number (percentage) $-\chi^{2}$ test; Survival rate is considered up to 30 days of life

severe TTTS using a smaller diameter cannula and fetoscope than has been utilized in previous reports. Although the results presented here were obtained during our initial experience and represent elements of a learning curve, they are encouraging since they are similar to those reported from experienced referral centers in the United States and Europe. ${ }^{19-25}$

Fetoscopic laser photocoagulation is usually performed using endoscopes from $1.2 \mathrm{~mm}$ to $3.3 \mathrm{~mm}$ in diameter that directly visualize the vessels on the placental surface. Once these inter-twin communicating vessels are identified, they are photocoagulated using laser energy. In our study, we used a smaller fetoscope and cannula of $1.0 \mathrm{~mm}$ and 2.2 $\mathrm{mm}$, respectively. To the best of our knowledge, this is the first report in which this less invasive technique was performed in all cases and even at gestational ages of longer than 21 weeks. One advantage of using a narrower cannula and endoscope might be the lower risk for premature rupture of the membranes and preterm labor. Additionally, the narrower apparatus might reduce maternal discomfort during procedures performed with local skin anesthesia. For these reasons, we decided to try this less invasive technique. However, several disadvantages of using a narrower and shorter endoscope have been suggested, including lower image quality, which was not observed in our study, and limited assessment of the deepest fetal or placental structures. In severe TTTS, this limitation is of particular concern when the placenta is posteriorly located and a severe polyhydramnios is present. In this situation, a slight amnioreduction was performed to reduce the distance between the tip of the endoscope and the placenta, thereby allowing assessment of superficial placental structures with the endoscope. Thus, placental superficial anastomoses were clearly identified in all cases in the present study.
Many studies that assess this type of treatment, including a recent meta-analysis, ${ }^{24,25}$ do not classify the severity of TTTS. However, it seems that laser therapy is superior to amnioreduction for stages II through IV. ${ }^{19-29}$ The optimal treatment for Stage I disease has not been determined. O'Donoghue et al. ${ }^{30}$ reported their observational experience for 46 pregnancies with stage I TTTS and found that the disease remained stable or regressed in $69.6 \%$ of cases. Survival rates were superior when compared to cases that progressed to at least stage III (30.4\%). However, a factor that could predict the progression of the disease was not identified. Huber et al. ${ }^{31}$ reported that even in cases of stage I TTTS, laser therapy is associated with improved perinatal outcomes.

We only applied our fetoscopic laser protocol to severe cases for two reasons. First, it is preferable to limit a new therapeutic option to only the most severe cases while an institution's healthcare workers are still becoming familiar with the new procedure. This logic is supported by the literature - indeed, laser therapy was initially only performed for stages II through IV. Many investigators have recently suggested that fetoscopic laser therapy might be associated with improved perinatal outcomes even for stage I patients; ${ }^{31}$ in fact, it appears that the best results are achieved for stages I and II. The second reason that we only included TTTS stages III and IV was the late diagnosis and referral to our unit; these factors probably explain the high frequency of stage IV disease in our series as compared to other published reports.

Our results are very similar to recent reports for stage III and IV patients (Table 2). For stage III, survival of at least one baby and both twins has been reported to range between $76.2 \%$ and $82.5 \%$ and between $19.1 \%$ and $53.8 \%$, respectively. ${ }^{19,31-33}$ This compares to the rates of $88.9 \%$ and $33.3 \%$, respectively, observed in the present study. For stage 
Table 2 - Comparison between our perinatal outcomes and those reported in the literature

\begin{tabular}{|c|c|c|c|c|c|}
\hline & & 0 survivor & 1 survivor & 2 survivors & At least 1 survivor \\
\hline & & $\mathrm{N}(\%)$ & $\mathrm{N}(\%)$ & $\mathrm{N}(\%)$ & $\mathrm{N}(\%)$ \\
\hline \multirow[t]{2}{*}{ Quintero et al. $2003^{32}$} & Stage III & $6 / 28(21.5 \%)$ & $15 / 28(53.6 \%)$ & $7 / 28(25.0 \%)$ & $22 / 28(78.6 \%)$ \\
\hline & Stage IV & $2 / 11(18.2 \%)$ & $4 / 11(36.4 \%)$ & $5 / 11(45.5 \%)$ & $9 / 11(81.8 \%)$ \\
\hline \multirow[t]{2}{*}{ Senat et al. $2004^{19}$} & Stage III & NR & NR & NR & $23 / 35(65.7 \%)$ \\
\hline & Stage IV & NR & NR & NR & \\
\hline \multirow[t]{2}{*}{ Huber et al. $2006^{31}$} & Stage III & $14 / 80(17.5 \%)$ & $23 / 80(28.7 \%)$ & $43 / 80(53.8 \%)$ & $66 / 80(82.5 \%)$ \\
\hline & Stage IV & $3 / 10(30.0 \%)$ & $2 / 10(20.0 \%)$ & $5 / 10(50.0 \%)$ & $7 / 10(70.0 \%)$ \\
\hline \multirow[t]{2}{*}{ Sepulveda et al. $2007^{33}$} & Stage III & $5 / 21(23.8 \%)$ & $12 / 21(57.1 \%)$ & $4 / 21(19.1 \%)$ & $16 / 21(76.2 \%)$ \\
\hline & Stage IV & $1 / 3(33.3 \%)$ & $1 / 3(33.3 \%)$ & $1 / 3(33.3 \%)$ & $2 / 3(66.7 \%)$ \\
\hline \multirow[t]{2}{*}{ The present study } & Stage III & $1 / 9(11.1 \%)$ & $5 / 9(55.6 \%)$ & $3 / 9(33.3 \%)$ & $8 / 9(88.9 \%)$ \\
\hline & Stage IV & $3 / 10(30.0 \%)$ & $5 / 10(50.0 \%)$ & $2 / 10(20.0 \%)$ & $7 / 10(70.0 \%)$ \\
\hline
\end{tabular}

NR: not reported

IV TTTS, the reported survival of at least one baby and both twins is between $66.7 \%$ and $81.8 \%$ and $33.3 \%$ and $50.0 \%$, respectively. ${ }^{19,31-33}$ In the current study, our rates of survival were $70.0 \%$ and $20.0 \%$, respectively.

Our results are encouraging since they were obtained while our caregiver teams were still on the learning curve for this new procedure. The main problem in our series was that patients were referred too late, and thus presented with more severe complications. Although terminations of pregnancy and selective reductions have been reported as management options for severe TTTS in some series, termination was not performed in any of our cases. Obstetric complications such as PPROM and spontaneous preterm labor occurred with similar frequencies to those described in literature. ${ }^{29,34}$
In conclusion, our initial institutional experience using a narrower endoscope for fetoscopic laser photocoagulation treatment of severe TTTS can be considered encouraging since we observed similar rates of obstetric complications and perinatal survival to those reported in literature. Therefore, we conclude that narrower and more delicate instruments can be used for endoscopic laser therapy in severe TTTS.

\section{ACKNOWLEDGEMENT}

We would like to thank Prof. Kenneth J. Moise Jr. from Texas Children's Fetal Center for the important revision of the present manuscript.

\section{REFERENCES}

1. Hack KE, Derks JB, Elias SG, Franx A, Roos EJ, Voerman SK, et al. Increased perinatal mortality and morbidity in monochorionic versus dichorionic twin pregnancies: clinical implications of a large Dutch cohort study. BJOG. 2008;115:58-67.

2. Wee LY, Muslim I. Perinatal complications of monochorionic placentation. Curr Opin Obstet Gynecol. 2007;19:554-60.

3. Acosta-Rojas R, Becker J, Munoz-Abellana B, Ruiz C, Carreras E, Gratacos E, et al. Catalunya and Balears Monochorionic Network. Twin chorionicity and the risk of adverse perinatal outcome. Int J Gynaecol Obstet. 2007;96:98-102.

4. De Lia JE. Surgery of the placenta and umbilical cord. Clin Obstet Gynecol. 1996;39:607-25.

5. Haverkamp F, Lex C, Hanisch C, Fahnenstich H, Zerres K. Neurodevelopmental risks in twin-to-twin transfusion syndrome: preliminary findings. Eur J Paediatr Neurol. 2001;5:21-7.
6. Johnsen SL, Albrechtsen S, Pirhonen J. Twin-twin transfusion syndrome treated with serial amniocenteses. Acta Obstet Gynecol Scand. 2004;83:326-9.

7. Leung WC, Wong KY, Leung KY, Lee CP, Tang MH, Lao TT. Successful outcome after serial amnioreductions in triplet fetofetal transfusion syndrome. Obstet Gynecol. 2003;101(5 Pt 2):1107-10.

8. Ling PY, Leo MV, Rodis JF, Campbell WA. Amnioreduction in triplet fetofetal transfusion. Obstet Gynecol. 2000;96(5 Pt 2):843.

9. Rodeck CH, Weisz B, Peebles DM, Jauniaux E. Hypothesis: the placental 'steal' phenomenon - a possible hazard of amnioreduction. Fetal Diagn Ther. 2006;21:302-6.

10. Saade GR, Belfort MA, Berry DL, Bui TH, Montgomery LD, Johnson A, et al. Amniotic septostomy for the treatment of twin oligohydramniospolyhydramnios sequence. Fetal Diagn Ther. 1998;13:86-93. 
11. Adegbite AL, Ward SB, Bajoria R. Perinatal outcome following amniotic septostomy in chronic TTTS is independent of placental angioarchitecture. J Perinatol. 2003;23:498-503.

12. Moise KJ Jr, Dorman K, Lamvu G, Saade GR, Fisk NM, Dickinson JE, et al. A randomized trial of amnioreduction versus septostomy in the treatment of twin-twin transfusion syndrome. Am J Obstet Gynecol. 2005;193(3 Pt 1):701-7.

13. Ross MG, van den Wijngaard JP, van Gemert MJ. TTTS amnioreduction versus septostomy. Am J Obstet Gynecol. 2006;195:881-2.

14. Johnson JR, Rossi KQ, O'Shaughnessy RW. Amnioreduction versus septostomy in twin-twin transfusion syndrome. Am J Obstet Gynecol. 2001:185:1044-7.

15. De Lia JE, Kuhlmann RS, Harstad TW, Cruikshank DP. Fetoscopic laser ablation of placental vessels in severe previable twin-twin transfusion syndrome. Am J Obstet Gynecol. 1995;172(4 Pt 1):1202-8; discussion 1208-11.

16. Ville Y, Hyett J, Hecher K, Nicolaides K. Preliminary experience with endoscopic laser surgery for severe twin-twin transfusion syndrome. $\mathrm{N}$ Engl J Med. 1995 26;332:224-7.

17. Ville Y, Hecher K, Gagnon A, Sebire N, Hyett J, Nicolaides K. Endoscopic laser coagulation in the management of severe twin-to-twin transfusion syndrome. Br J Obstet Gynaecol. 1998;105:446-53.

18. Lopriore E, Nagel HT, Vandenbussche FP, Walther FJ. Long-term neurodevelopmental outcome in twin-to-twin transfusion syndrome. Am J Obstet Gynecol. 2003;189:1314-9.

19. Senat MV, Deprest J, Boulvain M, Paupe A, Winer N, Ville Y. Endoscopic laser surgery versus serial amnioreduction for severe twin-to-twin transfusion syndrome. N Engl J Med. 2004 ;351:136-44.

20. Duncan KR. Twin-to-twin transfusion: update on management options and outcomes. Curr Opin Obstet Gynecol. 2005;17:618-22.

21. Nizard J, Gussi I, Ville Y. Maternal hemodynamic changes following treatment by laser coagulation of placental vascular anastomoses and amnioreduction in twin-to-twin transfusion syndrome. Ultrasound Obstet Gynecol. 2006;28(5):670-3.

22. Lenclen R, Paupe A, Ciarlo G, Couderc S, Castela F, Ortqvist L, et al. Neonatal outcome in preterm monochorionic twins with twin-to-twin transfusion syndrome after intrauterine treatment with amnioreduction or fetoscopic laser surgery: comparison with dichorionic twins. Am J Obstet Gynecol. 2007;196:450.e1-7.
23. Rossi AC, D'Addario V. Laser therapy and serial amnioreduction as treatment for twin-twin transfusion syndrome: a metaanalysis and review of literature. Am J Obstet Gynecol. 2008;198:147-52.

24. Roberts D, Neilson JP, Kilby M, Gates S. Interventions for the treatment of twin-twin transfusion syndrome. Cochrane Database Syst Rev. 2008;(1):CD002073.

25. Roberts D, Gates S, Kilby M, Neilson JP. Interventions for twin-twin transfusion syndrome: a Cochrane review. Ultrasound Obstet Gynecol. 2008;31:701-11.

26. De Lia JE, Cruikshank DP, Keye WR Jr. Fetoscopic neodymium:YAG laser occlusion of placental vessels in severe twin-twin transfusion syndrome. Obstet Gynecol. 1990;75:1046-53.

27. Quintero RA, Morales WJ, Allen MH, Bornick PW, Johnson PK, et al. Staging of twin-twin transfusion syndrome. J Perinatol. 1999;19(8 Pt 1):550-5.

28. Bruner JP, Anderson TL, Rosemond RL. Placental pathophysiology of the twin oligohydramnios-polyhydramnios sequence and the twin-twin transfusion syndrome. Placenta. 1998;19:81-6.

29. Yamamoto M, Ville Y. Laser treatment in twin-to-twin transfusion syndrome. Semin Fetal Neonatal Med. 2007;12:450-7.

30. O’Donoghue K, Cartwright E, Galea P, Fisk NM. Stage I twin-twin transfusion syndrome: rates of progression and regression in relation to outcome. Ultrasound Obstet Gynecol. 2007;30:958-64.

31. Huber A, Baschat AA, Bregenzer T, Diemert A, Tchirikov M, Hackelöer $\mathrm{BJ}$, et al. Laser coagulation of placental anastomoses with a 30 degrees fetoscope in severe mid-trimester twin-twin transfusion syndrome with anterior placenta. Ultrasound Obstet Gynecol. 2008;31:412-6.

32. Quintero RA, Dickinson JE, Morales WJ, Bornick PW, Bermúdez C, Cincotta R, et al. Stage-based treatment of twin-twin transfusion syndrome. Am J Obstet Gynecol. 2003;188:1333-40.

33. Sepulveda W, Wong AE, Dezerega V, Devoto JC, Alcalde JL. Endoscopic laser surgery in severe second-trimester twin-twin transfusion syndrome: a three-year experience from a Latin American center. Prenat Diagn. 2007;27:1033-8.

34. Crombleholme TM, Shera D, Lee H, Johnson M, D'Alton M, Porter $\mathrm{F}$, Chyu J, et al. A prospective, randomized, multicenter trial of amnioreduction vs selective fetoscopic laser photocoagulation for the treatment of severe twin-twin transfusion syndrome. Am J Obstet Gynecol. 2007;197:396.e1-9. 